\title{
Caracterización del nivel tecnológico y edad al primer estro de hembras Criollo Lechero Tropical
}

\section{Characterization of technological level and age at first estrus of Criollo Lechero Tropical females}

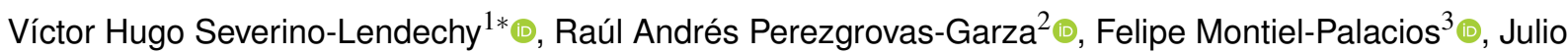

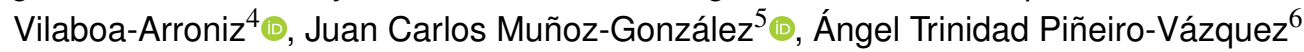

\footnotetext{
${ }^{1}$ Centro de Estudios Etnoagropecuarios, Universidad Autónoma de Chiapas. Blvd. Javier López Moreno s/n, CP. 29264. San Cristóbal de las Casas, Chiapas, México.

${ }^{2}$ Instituto de Estudios Indígenas, Universidad Autónoma de Chiapas. Blvd. Javier López Moreno s/n, CP. 29264. San Cristóbal de las Casas, Chiapas, México.

${ }^{3}$ Facultad de Medicina Veterinaria y Zootecnia, Universidad Veracruzana. Circunvalación Esq. Yáñez s/n, Col. Unidad Veracruzana, CP. 91710. Veracruz, Veracruz, México.

${ }^{4}$ Agroecosistemas Productivos S.P.R. de R.L. de C.V. Av. José María Morelos 910. Colonia Centro. CP. 95400. Cosamaloapan, Veracruz, México.

${ }^{5}$ Facultad Maya de Estudios Agropecuarios, Medicina Veterinaria y Zootecnia, Universidad Autónoma de Chiapas. Carretera Catazajá-Palenque. Km 4. CP. 29980. Catazajá, Chiapas, México.

${ }^{6}$ Tecnológico Nacional de México/Instituto Tecnológico de Conkal, División de Estudios de Posgrado e Investigación, Avenida Tecnológico s/n. CP. 97345. Conkal, Yucatán, México.

*Autor de correspondencia: vhseverino@hotmail.com
}

Nota científica recibida: 24 de julio de 2018 aceptada: 28 de enero de 2019

RESUMEN. El objetivo fue caracterizar el nivel tecnológico (NT), registrar la edad y peso al primer estro y primer servicio en vaquillas Criollo Lechero Tropical (CLT) en Méxio. Se emplearon nueve unidades de producción (UP). Las UP tuvieron un $33.3,44.4$ y $22.3 \%$ de NT bajo, medio y alto, respectivamente. La edad (meses) y peso al primer estro $(\mathrm{kg})$ según el NT de las UP fue de $20.0 \pm 3.0$ y $280.0 \pm 33.3$ para NT bajo, $18.2 \pm 1.64$ y $286.3 \pm 20.0$ para NT medio y, $15.0 \pm 1.6$ y 260.0 \pm 35.0 para NT alto, respectivamente. La edad (meses) y peso al primer servicio $(\mathrm{kg})$ según el NT de las UP fue de 22.1 \pm 2.0 y $310.0 \pm 25.3$ para NT bajo, $20.6 \pm 2.0$ y $319.5 \pm 22.6$ para NT medio y $17.5 \pm 1.5$ y $291.0 \pm 30.1$ para NT alto, respectivamente. La edad y peso al primer estro y primer servicio varía según el nivel tecnológico de la UP.

Palabras clave: Índice tecnológico, primer servicio, razas bovinas criollas, unidades de producción bovinas.

ABSTRACT. The aim was to characterize the technological level (TL), record age and weight at first estrus and first service in Criollo Lechero Tropical (CLT) heifers in Mexico. Nine production units (PU) were used. The PU have 33.3, 44.4, and $22.3 \%$ of low, medium, and high TL, respectively. Age (months) and weight at first estrus (kg) according to the TL of the PU were $20.0 \pm 3.0$ and $280.0 \pm 33.3$ for low TL, $18.2 \pm 1.64$ and $286.3 \pm 20.0$ for medium TL and $15.0 \pm 1.6$ and $260.0 \pm$ 35.0 for high TL, respectively. The age (months) and weight at first service $(\mathrm{kg})$ according to the TL of the UP were $22.1 \pm$ 2.0 and $310.0 \pm 25.3$ for low TL, $20.6 \pm 2.0$ and $319.5 \pm 22.6$ for medium TL and $17.5 \pm 1.5$ and $291.0 \pm 30.1$ for high TL, respectively. The age and weight at first estrus and first service vary according to the technological level of the PU.

Key words: Technology index, first service, race creoles bovines, bovine production units.

\section{INTRODUCCIÓN}

El ganado Criollo Lechero Tropical (CLT) presente en México es manejado principalmente por productores de la Asociación Mexicana de Criadores de Ganado Romosinuano y Criollo Lechero Tropical (AMCROLET), universidades y centros de investi- gación, que han tratado de conservarlo y desarrollarlo con el establecimiento de hatos experimentales, demostrativos y productivos (Vilaboa-Arroniz et al. 2012b). Esta raza, esta especializada en producción de leche a base de pastos naturales, adaptada a través de la selección natural a las condiciones ambientales adversas de las regiones tropicales 


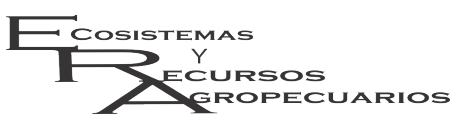

(Vilaboa-Arroniz et al. 2012a,b). Debido a la estacionalidad de la producción, se le atribuye precocidad, fertilidad, facilidad al parto y longevidad en comparación con razas cebú y europeas adaptadas a los trópicos, así como resistencia a enfermedades (De Alba 2011) y ectoparásitos (González-Cerón et al. 2009).

La información sobre aspectos de manejo zootécnico y la edad al primer estro de esta raza es escasa. Por lo que el interés de conservar y estudiar al ganado CLT no es sólo con fines académicos y de conservación; su estudio es importante para el desarrollo de sistemas productivos alternos en hatos bovinos del trópico mediante el uso y aprovechamiento de sus capacidades productivas (Vilaboa-Arroniz et al. 2012a,b). Por lo que es necesario diseñar estrategias que promuevan el uso del ganado CLT en México y Latinoamérica. Por ello, una opción para obtener información vigente y confiable de las hembras CLT fue trabajar con los socios de la AMCROLET, lo cual permitió determinar el manejo zootécnico del ganado CLT. Por lo anterior el objetivo del presente estudio fue caracterizar el NT, registrar la edad y peso al primer estro y primer servicio en hembras CLT.

\section{MATERIALES Y MÉTODOS}

\section{Selección de productores y ubicación de las unidades de producción}

El criterio de selección fue ser productor con animales CLT y estar registrado como miembro activo en la AMCROLET. Se entrevistó a directivos de la AMCROLET para obtener información de los productores con ganado CLT. Con base en lo anterior y con datos de dicha Asociación se seleccionaron nueve socios activos de la AMCROLET localizados en los estados de Veracruz, Guerrero, Tabasco y Chiapas, que cumplieran los siguientes criterios: 1) estar al día en sus cuotas como miembros de la asociación, 2) asistir a más del $70 \%$ de las asambleas y 3) tener registros productivos vigentes de sus animales (AMCROLET, 1998, 2010). Aunque el número de socios que manejan esta raza es escaso y disperso, el trabajo tiene importancia debido a
Severino-Lendechy et al. Nivel tecnológico y estro Ecosist. Recur. Agropec. 6(17):353-359,2019

que sentarán las bases para futuras investigaciones al conocer características socioeconómicas, componentes tecnológicos y parámetros productivos en las unidades de producción con la raza CLT. Se visitaron las UP localizadas en los municipios y localidades de Tamiahua, Tantoyuca, Tecolutla, Manlio Fabio Altamirano, Catemaco y Rinconada, Veracruz; uno en el municipio de Olinalá, Guerrero; otro en la localidad de Ixtacomitán 1ra Sección, Tabasco, y uno en el municipio de Huixtla, Chiapas. La Información específica relacionada con la localización de cada UP y sus características climáticas se muestran en la Tabla 1.

\section{Estructura del instrumento de evaluación}

El instrumento de evaluación fue un cuestionario estructurado con 21 preguntas distribuidas en cinco rubros que incluyeron: 1) Identificación del socio, 2) Aspectos socioculturales, 3) Aspectos socioeconómicos, 4) Aspectos tecnológicos y 5) Técnicoproductivas relacionadas con la edad y peso al primer estro y primer servicio de las hembras CLT (Doorman et al. 1991).

\section{Clasificación de las unidades de producción}

Se clasificaron nueve UP con base al municipio o localidad donde se encuentran ubicadas, como se enumera a continuación: 1) Tamiahua, 2) Tantoyuca, 3) Tecolutla, 4) Rinconada, 5) Manlio Fabio Altamirano, 6) Catemaco, 7) Olinala, 8) Ixtacomitán y 9) Huixtla.

\section{Clasificación de la información}

Se generó a partir de la metodología propuesta por Vilaboa y Díaz (2009), modificando el rubro tecnológico, el rango de puntaje según rubro tecnológico (Tabla 2) y NT. Primero se diseñó una base de datos en Excel 2016 Microsoft Office en donde se concentraron los datos obtenidos en campo, clasificándose y depurándose las variables. Posteriormente se identificaron los componentes tecnológicos utilizados en los ranchos ganaderos, a estos resultados se les realizó un análisis de componentes principales para compactar los datos e identificar la interdependencia entre variables, lo cual generó el rubro tecnológico. 
Tabla 1. Municipio, ubicación geográfica, clima, temperatura y precipitación media anual por unidad de producción donde se realizó la encuesta (Climate-Data 2019).

\begin{tabular}{|c|c|c|c|c|}
\hline Municipio & Ubicación geográfica & Clima & $\begin{array}{c}\text { Temperatura media } \\
\text { anual }\left({ }^{\circ} \mathrm{C}\right)\end{array}$ & $\begin{array}{c}\text { Precipitación media } \\
\text { anual (mm) }\end{array}$ \\
\hline 1) Tamiahua & $21^{\circ} 17^{\prime}$ LN y $97^{\circ} 27^{\prime}$ LO, 4 msnm & Tropical seco & 24.4 & 1379 \\
\hline 2) Tantoyuca & $21^{\circ} 21^{\prime} \mathrm{LN}$ y $98^{\circ} 14^{\prime} \mathrm{LO}, 140 \mathrm{msnm}$ & Tropical seco & 23.8 & 1210 \\
\hline 3) Tecolutla & $20^{\circ} 29^{\prime}$ LN y $97^{\circ} 00^{\prime}$ LO, 10 msnm & Tropical monzónico & 24.0 & 1497 \\
\hline 4) Rinconada & $19^{\circ} 21^{\prime}$ LN y $96^{\circ} 34^{\prime}$ LO, 215 msnm & Tropical seco & 24.6 & 939 \\
\hline 5) Manlio Fabio Altamirano & $19^{\circ} 12^{\prime}$ LN y $19^{\circ} 08^{\prime}$ LO, 10 msnm & Tropical seco & 24.4 & 1150 \\
\hline 6) Catemaco & $95^{\circ} 04^{\prime} \mathrm{LN}$ y $18^{\circ} 26^{\prime} \mathrm{LO}, 350 \mathrm{msnm}$ & Tropical monzónico & 23.8 & 2328 \\
\hline 7) Olinala & $17^{\circ} 47^{\prime}$ LN y $98^{\circ} 44^{\prime} \mathrm{LO}, 1,400 \mathrm{msnm}$ & Tropical seco & 22.3 & 944 \\
\hline 8) Ixtacomitán & $17^{\circ} 96^{\prime}$ LN y $92^{\circ} 96^{\prime}$ LO, 10 msnm & Tropical monzónico & 27.0 & 1958 \\
\hline 9) Huixtla & $15^{\circ} 08^{\prime}$ LN y $92^{\circ} 28^{\prime}$ LO, 28 msnm & Tropical monzónico & 27.8 & 3220 \\
\hline
\end{tabular}

Una vez determinadas las variables del rubro tecnológico se determinó el rango de puntaje, con un factor de ponderación arbitrario (Tabla 2). De lo cual se generó el nivel tecnológico en bajo (6-10 puntos), medio (11-15 puntos) y alto (16-20 puntos). Ya concentrada y compactada la información se realizó un análisis de agrupación (cluster), considerando las variables sociales y tecnológicas: edad, años de estudio, años de experiencia en la actividad ganadera, aspectos socioeconómicos y técnico-productivos. La información utilizada abarco los últimos 10 años de registros productivos y socioeconómicos que tenían disponibles los socios del año 2007 al 2017.

Tabla 2. Clasificación de componentes tecnológicos y rango de puntaje.

\begin{tabular}{lc}
\hline Rubro Tecnológico & $\begin{array}{c}\text { Rango de } \\
\text { puntaje }\end{array}$ \\
\hline Tipo de suplementación & $0-2$ \\
Tipo de animales & $0-2$ \\
Tiempo de suplementación & $0-2$ \\
Vacunación & $0-1$ \\
Desparasitación & $0-1$ \\
Campañas zoosanitarias & $0-1$ \\
Registros productivos y reproductivos & $0-1$ \\
Diagnóstico de mastitis & $0-1$ \\
Tipo de empadre & $0-2$ \\
Manejo de becerros & $0-2$ \\
Corrales de manejo & $0-1$ \\
Bodega & $0-1$ \\
Camioneta & $0-1$ \\
Bomba de agua & $0-1$ \\
Herramientas diversas & $0-1$ \\
\hline
\end{tabular}

\section{Análisis estadístico}

Los datos de edad, escolaridad, experiencia en el manejo de la raza, aspectos socioeconómicos y técnico-productivos se analizaron mediante estadística descriptiva, tablas de contingencia y análisis de agrupación (cluster). La edad y peso al primer estro y primer servicio se evaluaron mediante análisis de varianza utilizando el paquete estadístico SPSS versión 15.

\section{RESULTADOS Y DISCUSIÓN}

\section{Identificación del socio y aspectos sociocultu- rales según el nivel tecnológico de las unidades de producción \\ El $100 \%$ de los entrevistados fueron hom-} bres, con edad y escolaridad promedio de $56 \pm 15$ (máximo 71 y mínimo 26 años) y $15.8 \pm 4.1$ años, respectivamente (Tabla 3 ); el $22.2 \%$ pertenecían a instituciones de investigación (COLPOS y UNACH). Los resultados obtenidos son similares a los reportados por Vilaboa-Arroniz et al. (2012a), en Costa Rica, con edad y escolaridad en años de $57.0 \pm 5.0$ y 19.0 \pm 2.5 , respectivamente, lo que indica que los productores son gente adulta. En años de experiencia (Tabla 3) se han reportado diferencias (33.0 \pm 3.5$)$ y similitudes (24.0 \pm 14.0$)$ (Vilaboa y Díaz 2009), lo cual demuestra la heterogeneidad entre productores en regiones tropicales. La edad de los productores y los años de experiencia indican una falta de secuencia generacional, lo que ha sido reportado por Vilaboa-Arroniz et al. (2009), quienes lo atribuye a las condiciones de emigración de los jóvenes hacia actividades no relacionadas con el sector agrícola. 
Tabla 3. Edad, escolaridad y experiencia en el manejo de la raza Criollo Lechero Tropical según nivel tecnológico de las unidades de producción (Media $\pm \mathrm{DE}$ ).

\begin{tabular}{lcccc}
\hline Nivel tecnológico & UP & Edad (años) & Escolaridad (años) & Experiencia (años) \\
\hline Bajo (6-10 puntos) & 4,7 y 9 & $58.0 \pm 10.4$ & $13.3 \pm 8.1$ & $7.0 \pm 6.1$ \\
Medio (11-15 puntos) & $1,3,5$ y 6 & $58.5 \pm 22.1$ & $16.3 \pm 3.0$ & $23.3 \pm 16.2$ \\
Alto (16-20 puntos) & 2 y 8 & $48.5 \pm 6.4$ & $18.0 \pm 1.4$ & $9.5 \pm 6.4$ \\
Promedio & & $56.1 \pm 15.3$ & $15.8 \pm 4.1$ & $13.2 \pm 9.5$ \\
\hline
\end{tabular}

\section{Aspectos socioeconómicos según el nivel tec- nológico de las unidades de producción}

Debido a que dos de las UP contempladas en el estudio eran instituciones públicas (UNACH y COLPOS), fue necesario estandarizar la información obtenida, es decir, solo se consideró que la información estuviera disponible y los criterios empleados para el manejo de los ingresos-egresos y decisiones técnicas recayeron en la persona responsable del manejo del hato. Después de lo cual, la actividad socioeconómica se dividió en dos rubros con base a las fuentes de ingreso reportado por los productores: ingresos de la UP y trabajo remunerado (TR) fuera de la UP. El $55.5 \%$ de los productores perciben una parte de su ingreso de la UP y otra del TR (30 y 70\%, respectivamente); el $22.2 \%$ solo reciben ingresos del TR y el $22.2 \%$ solo reciben ingresos de la UP. Lo anterior, puede indicar que: 1) la mayoría de los productores independientemente del nivel tecnológico que tengan en su UP, no perciben a la ganadería como empresa, sino como negocio familiar que es heredado de padres a hijos y como fuente de ahorro para solventar gastos de emergencia y no dependen en su totalidad de la actividad ganadera (Díaz-Rivera et al. 2011); y 2) que las UP no son rentables, y por lo tanto, buscan otra fuente de ingresos, lo que se confirma porque el $77.7 \%$ de los productores, indicaron que la mayor parte de las inversiones que han realizado en la UP para implementar el uso de nuevas tecnologías provienen del TR. Al respecto, esto coincide con lo reportado en las UP en México y América latina, las cuales presentan en general una baja productividad generada por el manejo deficiente al que son sometidos los animales durante su vida productiva (González-Stagnaro et al. 2007), y la limitada o nula inversión en las UP (Vilaboa-Arroniz et al. 2009). Esto se atribuye los bajos precios pagados al productor y falta de fuentes de inversión tanto pública como privada, lo cual vuelve a la ganadería por un lado flexible y adaptable, ya que tiende a la producción de leche y/o carne conforme ocurren cambios en los precios del mercado (Gamboa et al. 2005). Pero por otro lado, limita su crecimiento, desarrollo y planificación estratégica (Vilaboa-Arroniz et al. 2009).

\section{Conformación del hato CLT de acuerdo con el nivel tecnológico de las unidades de producción}

Se realizó el inventario del hato de los productores entrevistados, observándose un buen desarrollo del hato en las UP, lo que se definió de acuerdo al porcentaje de vacas en producción comparadas con las vacas improductivas (horras) y el número de novillonas presentes con base en la tasa de reemplazo (Tabla 4). Las similitudes y diferencias encontradas en la composición del hato entre las UP, se deben a la heterogeneidad de los productores, al nivel tecnológico y tipo de manejo, que cada productor proporciona a sus animales durante su vida productiva (González-Stagnaro et al. 2007).

\section{Manejo general de las unidades de producción y los hatos de ganado Criollo Lechero Tropical}

El 78\% de los productores con ganado CLT manejan su ganado en el sistema de producción de doble propósito (DP) y sólo $22 \%$ tiene como objetivo la producción de leche, lo cual indica que aun cuando este ganado es una raza lechera, los productores lo manejan como la mayoría del ganado en el trópico, en el sistema de DP. El 33\% de los productores destina el $10 \%$ de la superficie de su UP como reserva ecológica, y $22 \%$ ocupan el $20 \%$ de su UP para sembrar caña de azúcar (Sacharum oficinarum) y maíz (Zea mays), cultivos utilizados para complementar alimenticia y nutricionalmente a los animales en la época de escasez de forraje o como complementación estratégica. El $22.3 \%$ de los produc- 
Tabla 4. Conformación del hato Criollo Lechero Tropical de acuerdo con el nivel tecnológico de las unidades de producción.

\begin{tabular}{ccccccccc}
\hline \multicolumn{10}{c}{ Nivel tecnológico } \\
\hline Composición del hato CLT & Bajo 4, 7 y 9 & $\%$ & Medio 1, 3, 5 y 6 & $\%$ & Alto 2 y 8 & $\%$ & Total & $\%$ \\
\hline Sementales & 5 & 2.5 & 21 & 3.6 & 13 & 2.2 & 39 & 2.8 \\
Vacas en ordeña & 36 & 18.3 & 159 & 27.4 & 325 & 54.5 & 520 & 37.9 \\
Vacas horras & 49 & 24.9 & 97 & 16.7 & 20 & 3.4 & 166 & 12.1 \\
Novillos & 1 & 0.5 & 33 & 5.7 & 0 & 0 & 34 & 2.5 \\
Novillonas & 59 & 29.9 & 124 & 21.4 & 114 & 19.1 & 297 & 21.6 \\
Becerros & 18 & 9.1 & 73 & 12.6 & 54 & 9.1 & 145 & 10.6 \\
Becerras & 29 & 14.7 & 73 & 12.6 & 70 & 11.7 & 172 & 12.5 \\
Total & 197 & 100 & 580 & 100 & 596 & 100 & 1373 & 100 \\
\hline
\end{tabular}

tores proporciona complemento alimenticio con concentrado y sales minerales de manera permanente a su hato, el $44.4 \%$ solo proporcionan sal mineral y el $33.3 \%$ suplementan con sal mineral a algunos animales y en forma esporádica. El 100\% realiza manejo zoosanitario, que consiste en prevención de enfermedades zoonóticas (brucelosis y tuberculosis), desparasitación interna (Levamisol, Lab. Genfar, dosis un $\mathrm{ml} / 20 \mathrm{~kg}$ de peso vía im; cada seis meses) y externa (Bayticol ${ }^{\circledR}$ Pouron 1\%, Lab. Bayer, dosis $10 \mathrm{ml} / 100 \mathrm{~kg}$ de peso vía tópica; cada $15 \mathrm{a}$ 30 días o según lo requieran los animales basándose en la infestación de garrapatas), vitaminación (Vigantol ${ }^{\circledR}$ ADE, Lab. Bayer, dosis cinco ml vía im; cada seis meses), y vacunación contra derriengue, fiebre carbonosa y carbón sintomático (Nobivac ${ }^{\circledR}$ Rabia, Lab. Intervet, dosis dos ml vía im, vacuna anticarbonosa, Lab. MSD, dosis un $\mathrm{ml}$ vía sc, Bacterina triple C.E.S. ${ }^{\circledR}$, Lab. MSD, dosis cinco ml vía im; cada seis meses, respectivamente), indicando que tienen conocimiento y cultura para prevenir las enfermedades presentes en la zona donde están sus UP.

El $90 \%$ desteta a los becerros entre seis y ocho meses de edad, y solo el $10 \%$ lo realiza a los tres meses de edad; el $22 \%$ proporciona suplementación mineral y alimento concentrado después del destete a las hembras. Los resultados muestran que la mayoría de los productores manejan de manera rústica o tradicional a sus animales de reemplazo; es decir, las becerras se alimentan práctica y exclusivamente de la leche de su madre hasta el destete (siete a ocho meses) y posteriormente reciben escasa o nula complementación alimenticia y mineral. El 100\% tiene registros productivos y reproductivos, pero solo el $70 \%$ los mantiene vigentes y actualizados, indicando que en su mayoría conocen el historial de sus animales. El 100\% realiza empadre con monta directa (MD), $90 \%$ de manera permanente y $10 \%$ por época; adicionalmente al empadre con MD el $44 \%$ de los productores utiliza inseminación artificial (IA) y el $67 \%$ realiza diagnóstico de gestación, ya que cuentan con instalaciones y equipo necesario para esta actividad. Las características de manejo anteriormente descritas en las UP con ganado CLT son similares a las reportadas para otras UP en condiciones tropicales (González-Stagnaro et al. 2007, Vilaboa y Díaz 2009). Las diferencias encontradas en los NT (alto, medio y bajo) entre las UP (pastizales, alimentación, registros, manejo, sanidad, reproducción, instalaciones y equipo), son atribuibles a la heterogeneidad que hay entre los productores en regiones tropicales (Vilaboa-Arroniz et al. 2009). Estas diferencias radican principalmente en la utilización de componentes tecnológicos, finalidad productiva (leche, carne y DP), superficie pecuaria, unidades animal, carga animal, venta de animales por año y si la UP pertenece a un particular o a una Institución (Vilaboa y Díaz 2009, Vilaboa-Arroniz et al. 2012a). Estos aspectos confieren particularidades en los procesos de innovación, adopción de tecnología y rentabilidad de la UP (Vilaboa-Arroniz et al. 2009, Vilaboa y Díaz 2009).

\section{Información técnico-productiva de edad y peso al primer estro y primer servicio según nivel tec- nológico}

La información técnico-productiva relacionada con la edad y peso al primer estro y primer servicio 
Tabla 5. Promedio de edad, peso al primer estro y primer servicio de vaquillas Criollo Lechero Tropical en las unidades de producción según nivel tecnológico (Media $\pm \mathrm{DE}$ ).

\begin{tabular}{lcccc}
\hline \multicolumn{4}{c}{ Nivel tecnológico } \\
\hline Variable & Bajo 4, 7 y 9 & Medio 1, 3, 5 y 6 & Alto 2 y 8 & Promedio \\
\hline Edad al primer estro (meses) & $20.0 \pm 3.0^{a}$ & $18.2 \pm 1.64^{b}$ & $15.0 \pm 1.6^{c}$ & $18.1 \pm 3.9$ \\
Peso al primer estro (kg) & $280.0 \pm 33.3^{a}$ & $286.3 \pm 20.0^{b}$ & $260.0 \pm 35.0^{c}$ & $278.0 \pm 25.5$ \\
Edad al primer servicio (meses) & $22.1 \pm 2.0^{a}$ & $20.6 \pm 2.0^{b}$ & $17.5 \pm 1.5^{c}$ & $20.0 \pm 2.0$ \\
Peso al primer servicio (kg) & $310.0 \pm 25.3^{a}$ & $319.5 \pm 22.6^{b}$ & $291.0 \pm 30.1^{c}$ & $306.8 \pm 26.0$ \\
\hline a, b, c Diferente literal entre filas indica diferencia estadística $(\mathrm{p}<0.05)$. &
\end{tabular}

en hembras CLT, no permite garantizar que las hembras bovinas estudiadas hayan sido pre-púberes de manera previa a la obtención de la información relacionadas a estas variables de estudio (edad y peso al primer estro), lo cual es consecuencia de la naturaleza de la investigación, que se basó en la consulta de registros reproductivos. Sin embargo, si indicó el manejo nutricional y reproductivo al que son sometidas las hembras en cada UP, así, se observó que en las UP con NT medio y alto, las hembras son complementadas nutricionalmente después del destete con alimento balanceado $\mathrm{y} / \mathrm{o}$ forraje $\mathrm{u}$ ambos y posteriormente son enviadas a empadre. La edad y peso al primer estro se definió cuando los productores observaron en celo a las hembras por primera vez. Sin embargo, en todas las UP, independientemente del NT las hembras no reciben monta en este momento, debido a que los productores consideran que los animales tienen poca talla (tamaño y peso) para ser gestadas y en general esperan de dos a tres meses en promedio, después de ser observadas en celo por primera vez, para recibir el primer servicio (MD o IA) (Tabla 5).

Las hembras en las UP con NT bajo presentan el primer estro a mayor edad que las UP con NT medio y alto, lo que causa que la edad al primer servicio sea mayor. A su vez, las hembras en UP con NT medio el primer estro lo presentan a menor edad comparadas con las UP con NT bajo, pero a mayor edad que las hembras manejadas en UP con NT alto. El peso al primer estro de las hembras en UP con NT bajo es menor comparadas con las manejadas en
UP con NT medio, pero mayor que las de UP con NT alto, debido a que las hembras en UP con NT alto presentan el primer estro a edad más joven comparadas con las UP con NT bajo y medio, y por lo tanto tienen menos peso (Tabla 5). Estas diferencias se atribuyen al NT y al manejo nutricional, que cada UP somete a sus becerras, antes y después del destete (González-Stagnaro et al. 2007), sugiriendo que la alimentación es uno de los factores más importantes que determina la edad y peso al primer estro de las hembras CLT. El promedio de edad, peso al primer estro y primer servicio de las hembras CLT según la información técnico-productiva de los productores, indica que el primer estro se alcanza a una edad más joven y por lo tanto inician su vida productiva antes, comparadas con otras razas (Bos taurus, Bos indicus y sus cruzas) presentes en el trópico, en donde la edad y peso a la pubertad se reportan que es mayor a los 30 meses y con pesos que van de 300 a $350 \mathrm{~kg}$, lo que ocasiona que el primer parto se tenga a los 42 \pm 6 meses (Vite et al. 2007, Maquivar y Galina 2010, De Alba 2011). Lo que muestra la precocidad de las hembras CLT manejadas en el trópico.

El manejo zootécnico que recibe el ganado CLT, propiedad de los socios de la AMCROLET es similar a la de otras razas presentes en el trópico. La edad y peso al primer estro y primer servicio varía según el NT de la UP. El manejo nutricional que reciben las vaquillas en la UP es el principal factor que afecta la edad al primer estro y al primer servicio de las hembras CLT.

\section{LITERATURA CITADA}

AMCROLET (1998) Reglamento técnico de la Asociación Mexicana de Criadores de ganado Romosinuano y Lechero Tropical. Asociación Mexicana de Criadores de Ganado Romosinuano y Criollo Lechero Tropical. 
México. 12p.

AMCROLET (2010) Archivo inventario bovino octubre 2010. Asociación Mexicana de Criadores de Ganado Romosinuano y Criollo Lechero Tropical.Veracruz, México. 34p.

Climate-data (2019) Clima México. https://es.climate-data.org/america-del-norte/mexico-179/. Fecha de consulta: 15 de enero 2019.

De Alba J (2011) Los Criollos Lecheros Tropicales. In: de Alba-Martínez J (ed.) El libro de los bovinos criollos de América. Ediciones Papiro Omega. Biblioteca Básica de Agricultura. Colegio de Postgraduados. México. pp: 91-156.

Díaz-Rivera P, Oros-Noyolaa V, Vilaboa-Arroniza J, Martínez-Dávila JP, Torres-Hernández G (2011) Dinámica del desarrollo de la ganadería doble propósito en las Choapas, Veracruz, México. Tropical and Subtropical Agroecosystems 14: 191-199.

Doorman F, Miranda RF, De Nie C, Ooijens J, Ovares RL, Ramírez AC, et al. (1991) La metodología del diagnóstico en el enfoque "Investigación Adaptativa". Guía para la ejecución de un diagnóstico con énfasis en el análisis de finca del pequeño productor agropecuario. Universidad Nacional Heredia, Universidad Estatal de Utrecht, IICA. Costa Rica. 301p.

González-Cerón F, Becerril-Pérez CM, Torres-Hernández G, Díaz-Rivera P (2009) Garrapatas que infestan regiones corporales del bovino Criollo Lechero Tropical en Veracruz, México. Agrociencia 43: 11-19.

González-Stagnaro C, Madrid-Bury N, Goicochea-Llaque J, González-Villalobos D, Rodríguez-Urbina MA (2007) Primer servicio en novillas de doble propósito. Revista Científica Facultad de Ciencias Veterinarias LUZ 17: 39-46.

Gamboa J, Magaña M, Rejón M, Pech V (2005) Eficiencia económica de los sistemas de producción de carne bovina en el municipio de Tizimín, Yucatán, México. Tropical and Subtropical Agroecosystem 5: 79-84.

Maquivar M, Galina CS (2010) Factors Affecting the readiness and preparation of replacement heifers in tropical breeding environments. Reproduction of Domestic Animals 45: 937-942.

Vilaboa J, Díaz P (2009) Caracterización socioeconómica y tecnológica de los sistemas ganaderos en siete municipios del estado de Veracruz, México. Zootecnia Tropical 27: 427-436.

Vilaboa-Arroniz J, Díaz-Rivera P, Ruiz-Rosado O, Platas-Rosado DE, González-Muñoz S, Juárez-Lagunes F (2009) Caracterización socioeconómica y tecnológica de los agroecosistemas con bovinos de doble propósito de la región del Papaloapan, Veracruz, México. Tropical and Subtropical Agroecosystems 10: 53-62.

Vilaboa-Arroniz J, Quirós-Madrigal O, Díaz-Rivera P, WingChing-Jones R, Brower-Keating N, Zetina-Córdoba P (2012a) Los sistemas ganaderos con criollo lechero tropical (Reyna) en Costa Rica. Agronomía Mesoamericana 23: 167-178.

Vilaboa-Arroniz J, Quirós-Madrigal OJ, Díaz-Rivera P, Zetina-Córdoba P (2012b) Situación del bovino criollo lechero tropical (CLT) en México, Nicaragua y Costa Rica. Archivos de Zootecnia 61: 31-39.

Vite C, López R, García-Muñiz JG, Ramírez R, Ruíz A, López R (2007) Producción de leche y comportamiento reproductivo de vacas de doble propósito que consumen forrajes tropicales y concentrados. Veterinaria México 38: 63-79. 
